\title{
Synonymous with leading edge imaging equipment
}

Dürr Dental will be exhibiting a range of their equipment at this year's exhibition. Their brand is synonymous with leading edge imaging equipment. Their panoramic device is so easy to use you won't need a second take, as the first one will almost certainly be perfect. Unlike other devices this unit does not rely on experience or expertise, in fact both are almost negligible! Come and experience the difference yourself. You'll also get a chance to experiment with a totally new piece of imaging equipment!

Visitors might also be interested in the latest networking systems that can be used with your compressor and suction system. By linking them to the network, practices can see the performance of each piece of equipment at a glance. Linking the compressor, for example, to the digital network yields numerous benefits: current status, faults or messages, such as for filter changes, are immediately displayed.

Visit Dürr Dental on stand L76.

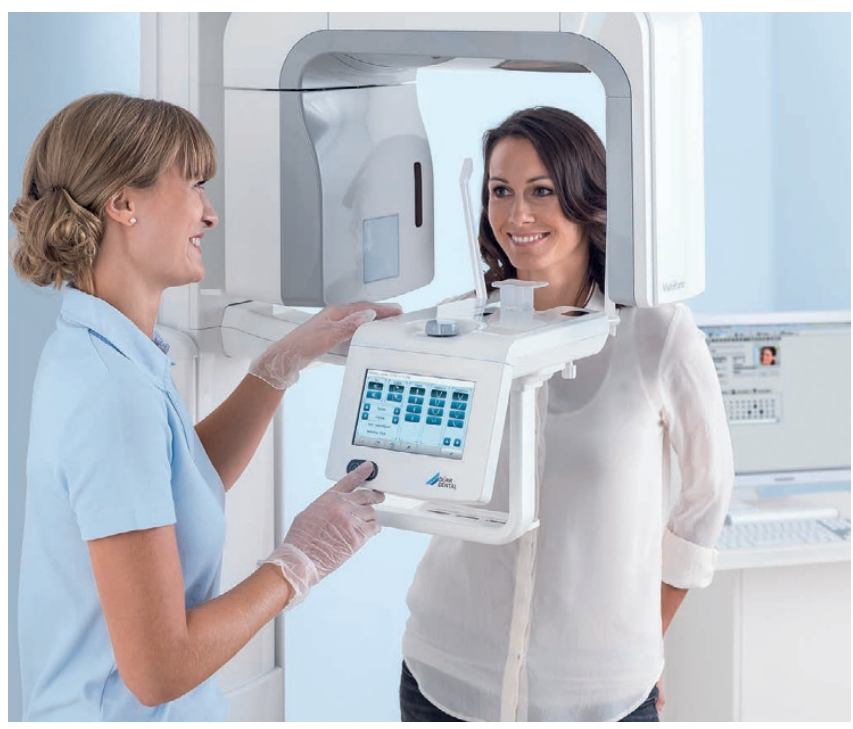

\section{Luxury upholstery in 48 colours}

Belmont invites you to take a seat on one of its stunning treatment centres. Their flagship Cleo II features a unique folding leg rest, which has a much smaller footprint than a conventional chair and is also far more familiar in design to patients, and thereby less intimidating.

For those requiring the flexibility of an ambidextrous unit, there's either the tbCompass or the Voyager III. With Belmont treatment centres you also have a huge array of colours from which to choose - 48 in total! There's an option for standard or luxury ultrasoft upholstery, so you can co-ordinate perfectly with the rest of your interior.

With your patient perfectly positioned, you need an operating light that will provide a flooded area of illumination, with minimum heat transfer and white light, which most closely matches daylight. The 900 LED light from Belmont does just that and its elegant design complements their treatment centres perfectly.

Visit Belmont on stand L50.

\section{Splint therapy and occlusion seminars}

Dr Glassman is a dentist located in Pennsylvania, USA. His private practice is limited to chronic pain management, TMD and dental sleep medicine. He has a comprehensive lecture programme in the USA and internationally covering these subjects.

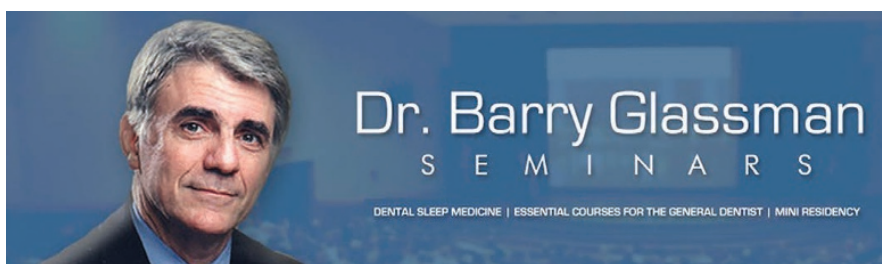

S4S are delighted to invite Dr Glassman back for a sixth year to present a series of lectures on the subject of bruxism and associated dental issues. This year Dr Glassman will be speaking in London on 27 and 28 October. In a nutshell, the sessions are for every dentist wanting to learn the truth (and be willing to unlearn some of the dogma that has been taught to us as professionals over the years) about TMD and occlusion. On day one there will be an overall in depth review of TMD, occlusion, bruxism and pain management, combining clinical experience with the current science. We will look at practical approaches to pain and dysfunction management. Attendees will have the opportunity to discuss their own cases. Day two will be a re-cap of day one followed by a hands-on session fitting SCi appliances and adjusting them on each other.

www.s4sdental.com

\section{Integrated practice solutions}

The CS R4+ practice management software from Carestream Dental is one owf the company's many innovations designed specifically to make your life easier.

For more information on the new R4 plus Springboard version 6.0, don't miss the team at BDIA Dental Showcase this year.

All current customers will benefit from the five new 'can see, can do' KPIs, helping every practice to monitor their performance more easily. Discover how you can properly use the cutting-edge technology to increase revenue potential and drive your business success.

Additional key features of the latest update include DEPPA integration with the CS R4+ software and improved SMS services for an even more reliable recall system and reduced 'no-shows'. What's more, the soon to be available eSignature module will be compatible with Scottish NHS PR forms, as well as treatment plans and medical history documents.

The newly improved CS R4+ software will continue to ensure simple integration throughout practices, seamlessly connecting with the range of cutting-edge technologies from Carestream Dental including the CS 3600 intraoral scanner, CS 8100 3D and CS 7200 imaging plate system.

To find out more, don't miss Carestream Dental at BDIA Showcase on stand L10.

For more information contact Carestream Dental on 08001699692 or visit www.carestreamdental.co.uk. 